\title{
Both aggressive and affiliative behaviour facilitate resource access in high-ranking female long-tailed macaques (Macaca fascicularis)
}

\author{
Anne M. Overduin-de Vries ${ }^{\mathrm{a}, \mathrm{b}}$, Han de Vries ${ }^{\mathrm{a}}$, Marjolijn M. Vermande ${ }^{\mathrm{c}}$, \\ Albert H.A. Reijntjes ${ }^{c, d}$ and Elisabeth H.M. Sterck ${ }^{a, b, *}$ \\ ${ }^{a}$ Animal Ecology, Utrecht University, Utrecht, The Netherlands \\ ${ }^{b}$ Biomedical Primate Research Centre, Rijswijk, The Netherlands \\ ${ }^{c}$ Education and Pedagogy, Utrecht University, Utrecht, The Netherlands \\ ${ }^{d}$ Developmental Psychology, Utrecht University, Utrecht, The Netherlands \\ *Corresponding author's e-mail address: e.h.m.sterck@uu.nl
}

Received 17 May 2019; initial decision 14 September 2019; revised 20 January 2020; accepted 20 January 2020; published online 4 February 2020

\begin{abstract}
Access to limited resources may be achieved by dominance as well as by high rates of aggressive and affiliative behaviour. We investigated the relative effectiveness of dominance rank and aggressive and affiliative behaviour in accessing three material and three social resources. Aggressive and affiliative behaviour of 24 female long-tailed macaques was scored along with their success in resource access. Path models revealed that high-ranking individuals have more access to resources than low-ranking ones through their employment of both aggressive and affiliative behaviour. Physical aggression was effective in accessing two material resources (food and enrichment). Affiliative behaviour was effective in accessing one material (co-drinking) and one social (tolerance) resource. In conclusion, since aggressive behaviour was effective in accessing two material resources, while affiliative behaviour increased access to both a material and a social resource, affiliative behaviour is at least as important as aggressive behaviour for high-ranking individuals to access resources.
\end{abstract}

\section{Keywords}

behavioural strategies, social behaviours, competition, monopolization.

\section{Introduction}

Access to scarce resources within a group of animals is very often skewed. This is especially the case in hierarchically structured groups, where high- 
ranking individuals typically access more limited resources than low-ranking ones (e.g., chickens: Banks et al., 1979; crayfish: Herberholtz et al., 2007; reviewed in: Huntingford \& Turner, 1987). Resource access may depend on the rate with which social behaviours are performed. In primates, more aggressive animals typically have more access to food (e.g., Wilson, 1975; Drews, 1993), and individuals which maintain friendships receive more social benefits (e.g., protection: Palombit et al., 1997). Similarly, developmental psychologists have shown that children can increase their access to resources, such as video watching, through the use of aggressive and/or affiliative behaviour (Charlesworth, 1996; Hawley, 1999; Pellegrini, 2008). Recent studies among children found that bistrategic individuals, i.e., children that show high rates of both aggressive and affiliative behaviour, are most successful in accessing resources (e.g., Hawley, 2003; Olthof et al., 2011; Roseth et al., 2011). Such dual use of both aggressive and affiliative behaviour may also be present in animals. However, in animals the influence of aggressive and affiliative behaviours on resource access are typically investigated separately.

Different types of social behaviour may increase access to different types of resources. The distinction made in child studies (Charlesworth, 1996; Hawley, 2003) between material resources (e.g., food), and social resources, (e.g. friends and allies) may also be useful when studying non-human primates. Indeed, aggression can be a successful way for an animal to gain access to food and other material resources (Janson, 1985; Boccia et al., 1988; Isbell, 1991; Sterck \& Steenbeek, 1997), while it may be more effective to employ affiliative behaviour when soliciting for grooming or other social resources such as being tolerated near food sources (Tiddi et al., 2011) or handling of infants (Henzi \& Barrett, 2002). Thus, different types of social behaviour may lead to resource access, yet a particular type of social behaviour may have more influence on access to a particular type of resource than other types of social behaviour.

An animal's aggression rate increases its access to material resources (capuchin monkeys, Cebus apella: Janson, 1985; bonnet macaques, Macaca radiata: Boccia et al., 1988; comparative research: Isbell, 1991; long-tailed macaques, M. fascicularis and Thomas langurs, Presbytis thomasi: Sterck \& Steenbeek, 1997), yet there is mixed evidence whether it also helps to access social resources. Males may gain mating access by forcing females (orangutans, Pongo pygmaeus: Mitani, 1985; chimpanzees, Pan troglodytes, 
Muller et al., 2011; Sonso group: Kaburu et al., 2015), yet other studies report that the relationship between aggression and mating is a by-product of proximity (Japanese macaques, M. fuscata: Soltis et al., 1997) or males may groom females to gain mating access (chimpanzees, M group: Kaburu et al., 2015). In addition, aggression may lead to grooming (Japanese macaques: only non-kin group members: Schino et al., 2005; Barbary macaques, $M$. sylvanus: Carne et al., 2011), yet more often the converse relationship is assumed and the effect of grooming on aggression is explored. These studies report that grooming may reduce aggression (long-tailed macaques: Gumert $\&$ Ho, 2008) or may not affect aggression (Japanese macaques: Schino et al., 2005; Ventura et al., 2006). Moreover, the effect of aggression may depend on the type of aggression. Aggression comprises both physical aggression and the mere threat of aggression. Physical aggression will in particular be useful to monopolize material resources, since other individuals will not attempt to access resources if they risk being physically attacked. Aggression exerted via threat behaviour is less costly than overt aggression (Cant \& Young, 2013). Primates are proficient in resolving conflicts with threat behaviour rather than physical fights (van Staaden et al., 2011). Particularly females, more often than males, resolve conflicts by means of threat behaviour rather than physical aggression (Cant \& Young, 2013) and may thus use threats to access resources. In short, it is predicted that both types of aggression lead to access to material resources, while the link with social resources requires further exploration.

Traditionally, affiliation has been studied in relation to gaining support in conflicts. Indeed, significant positive correlations between affiliation given and support received in a dyad are typically found (meta-analysis primates: Schino, 2007). Yet the benefits of affiliation may be broader, as suggested by the fitness benefits of affiliative behaviour (primates: Silk, 2002; Massen et al., 2010; Seyfarth \& Cheney, 2012; other mammals and social birds: Freidin et al., 2017). Affiliation, expressed as friendly or neutral approaches and grooming behaviour (ring-tailed lemurs, Lemur catta: Kulahci, et al., 2018), may result in receiving benefits such as others tolerating this affiliative individual near valuable resources (capuchin monkeys: Tiddi et al., 2011), or sharing of resources such as food (Japanese macaques: Ventura et al., 2006; Barbary macaques: Carne et al., 2011; review primates: Cronin, 2012; rhesus macaques, M. mulatta: Snyder-Mackler et al., 2016; barn owls, Tyto alba: 
Roulin et al., 2016) and at drinking locations (rhesus macaques: Balasubramaniam \& Berman, 2017) or reciprocating of friendly behaviour (Freidin et al., 2017) and accepting reconciliation (review: Aureli et al., 2002; rhesus macaques: Kempes et al., 2009). In this way, tolerance is a social resource that can be provided by the individual that receives affiliation. Therefore, it is predicted that affiliation leads to access to both material and, in particular, social resources, such as being tolerated close to food.

Animals with high dominance status typically have better access to monopolizable resources (Huntingford \& Turner, 1987) and higher reproductive success (review primate males: Alberts, 2012; review primate females: Pusey, 2012). Dominant individuals can gain access to a material resource because others avoid them or defer voluntarily (Schaub, 1995). In addition, dominant individuals can receive social beneficial behaviours like grooming, because others prefer to be in their proximity to gain access to resourses or receive support (Seyfarth, 1977; Kummer, 1978; Schino \& Lasio, 2018). Thus, dominance rank may be directly related to resource access, irrespective of the behaviour performed by the dominant individual, or indirectly, because high-ranking individuals are less constrained to deploy their social behaviour than low-ranking ones (c.f., Seyfarth, 1977). Therefore, it is predicted that higher dominance rank leads to more access to resources both directly (through their dominance position) and indirectly (through their behaviour).

Currently, the relative effectiveness of aggressive and affiliative behaviour on resource access requires further attention. Several studies indicate that both aggressive and affiliative behaviour may operate simultaneously (Japanese macaques: Schino et al., 2005; Ventura et al., 2006; long-tailed macaques: Gumert \& Ho, 2008; Barbary macaques: Carne et al., 2011). Individuals may differ in the rate with which they perform these types of behaviour and high dominance rank may promote an individual's potential to use both aggressive and affiliative behaviour. Therefore, it is important to study aggressive and affiliative behaviours at the same time and control for each other's effects on resource access (human children: Vermande et al., 2018), as well as for the possible effect of dominance rank. In addition, it is unknown how the relative effectiveness of these types of social behaviour may differ across different types of resources (material or social).

The current study addresses the effect of dominance and individual behavioural tendencies in expressing different types of social behaviour on 
resource access in captive group-living long-tailed macaques. In macaques, females are philopatric and they inherit their dominance rank through maternal support (Kawai, 1958a, b), forming a linear dominance hierarchy. The long-tailed macaques are considered quite intolerant (class 2: Thierry, 2007) and wild females have been shown to compete for food (van Noordwijk \& van Schaik, 1987; van Schaik \& van Noordwijk, 1988). In particular, this study aims to evaluate the possible effects of dominance rank, aggressive behaviour (differentiating between physical aggression and threat behaviour) and affiliative behaviour (differentiating between neutral/friendly approaches and grooming given) on access to different types of resources: material resources (i.e., food and non-food), and social resources (i.e., tolerance and grooming received). To this end, we employ path models in which we examine the effects of the factors dominance and the two different types of social behaviour on resource access. These models allow us to differentiate between direct effects of these factors on resource access and indirect effects, such as dominance influencing behaviours, which in turn influence resource access. This gives us information about the relative importance of dominance and social behaviours for getting access to specific resources. We expect that aggression is effective in accessing material resources and that physical aggression and threat behaviour are equally successful. In addition, we expect that affiliative behaviours are more effective in accessing social resources than aggressive behaviours. Finally, although we expect dominance rank to have an effect on resource access, we have no a priori expectations as to whether this effect remains significant after controlling for the effects of the social behaviours.

\section{Methods}

\subsection{Subjects}

Two social groups of long-tailed macaques (Macaca fascicularis) with a naturalistic composition were studied in their home enclosure at the Biomedical Primate Research Centre, Rijswijk, The Netherlands. Female group composition resembled that of wild females, since husbandry mimics natural demographic processes and allows females to remain in their natal groups and form matrilines, males are removed around puberty and adult males are replaced around every 5 years to avoid inbreeding. The first group, the 'Roza group', was studied from March until July 2014, the second group, the 'Haas 
group', was studied between February and June 2015. For our analyses we only selected females, since social behaviour differs between the sexes (Cant \& Young, 2013), like it does in children (Roseth et al., 2011). Moreover, motivation to access resources may differ between the sexes, since females' access to food limits their reproductive output, while male reproductive output depends mostly on access to mates (Pusey \& Schroepfer-Walker, 2013). We studied 24 female long-tailed macaques ranging from 2.5 to 24 years of age; 13 from the 'Roza group' and 11 from the 'Haas group'.

Subjects were able to walk freely between an interconnected indoor (108 $\mathrm{m}^{2}, 3 \mathrm{~m}$ high) and outdoor enclosure (209 $\mathrm{m}^{2}, 3 \mathrm{~m}$ high). During the enrichment experiment (see below) the inside compartments were closed off to prevent the monkeys from taking the resource out of view of the outside observer. Food was provided twice a day: in the morning monkey chow and in the afternoon apples (the food experiment), other fruit, or bread. Water was available ad libitum.

Dominance rank was established on the basis of dyadic unprovoked submissive behaviour (cf. Angst, 1974; i.e., bared-teeth display, make room and give ground). Note that this way of dominance rank determination neither includes aggressive behaviour nor any measure of resource access. The dominance hierarchy was established within both groups (Roza and Haas group, respectively) using MatMan (de Vries et al., 1993) and was significantly linear $\left(h^{\prime}=0.51,0.83 ; p=0.001,0.0001\right.$; directional consistency index $=$ 0.90, 0.98) (de Vries, 1995, 1998). The lowest ranking female got rank 0 and higher-ranking ones were given subsequent integers (Roza: to rank 12; Haas: to rank 10). In other words, the social rank of a female is the number of females dominated within each group.

\subsection{Social behaviour}

We determined individual behavioural tendencies of all subjects by recording aggressive and affiliative behaviour during observations of the subject's spontaneous behaviour within their home group. The two observers were trained by the same expert and did an interobserver reliability. The IOR was reasonable (point behaviours: $K=0.670, p<0.0005, N=151$; duration behaviours: Spearman: $\rho=0.753, p<0.0005, N=26$ ). Two different observation methods (Altmann, 1974) were used: (1) the focal animal sampling method, in which each subject was followed during 15 minute samples in a randomized order and balanced over the day while all aggressive and 
affiliative behaviours displayed by the focal individual were recorded; and (2) the all occurrence observations, consisting of one hour observations during which all occurrences of aggressive behaviours of all individuals were recorded. This dual method enabled us to monitor both frequent behaviours in the focal animal sampling method, as well as infrequent behaviours in the all occurrence observations. We collected $7.5 \mathrm{~h}$ of focal sampling for each focal individual. For each all occurrence observation, the observer conducted observations in a semi-random order in the outside or the inside enclosures, to achieve a balanced data set, and constantly recorded the presence of all individuals in the observed enclosure. In both groups $80 \mathrm{~h}$ of all occurrence observations resulted in a mean $38 \pm 3.9$ and $57 \pm 2.3 \mathrm{~h}$ of observation per individual, in the Haas and Roza group, respectively. All scored behaviours for a particular individual were divided by the time that the individual was observed.

Social behaviour was recorded when it occurred between one of our female focal animals and their group members: males and females from 2.5 to 24 years old. We distinguished between two types of aggressive behaviours that differed in the severity of aggression: physical aggression and threat behaviour. Physical aggression included behaviours that may possibly have direct physical consequences for the recipient, such as injury or weariness: chase, slap, push and pull (cf., Angst, 1974). Threat behaviour does not have such direct consequences: open mouth, stare, point and lunge (cf., Angst, 1974). We included two affiliative behaviours: grooming given: the time spend grooming another individual (cf., Angst, 1974); and neutral/friendly approaches: the number of approaches to other individuals within an arm's reach and included neutral proximity or affiliation (lip-smacking, lifting or grooming; Angst, 1974) from the approaching individual to the approached individual, but excluded approaches accompanied by aggressive interactions.

\subsection{Measures of resource access}

Three material resources (food, enrichment, drink) and three social resources (tolerance received during feeding time, tolerance received during enrichment situations, and grooming received) were examined. The material resources, having a limited availability, were familiar to and appreciated by the monkeys (Vernes \& Louwerse, 2010).

Behaviour during exposure to five of these resources (a-e) was recorded with a video camera (JVC HD Everio). Access to the resources was scored afterwards from the videos. 
(a) Food: Within each group, apples were given, one piece of apple at a time, by one and the same animal caretaker twice a week, with a total of 20 times. The food experiment uses the daily feeding routine in a restricted location of the indoor cage, while the animals still had access to the full enclosure. We registered how many apple pieces each monkey obtained.

(b) Enrichment: Five times per group, about once every two weeks, an enrichment object, viz., a phone book, was provided in one piece in the outside enclosure and was soon torn apart. This non-food enrichment object generated the interest of all group members. We registered for 30 min how much time each monkey spent manipulating one of the two largest pieces of the phone book. After this time typically no large parts remained.

(c) Drink: The lemonade co-drinking experiment (cf., de Waal, 1986; Amici et al., 2012) has been conducted twenty times for each group, with a frequency of about three times a week. Two bottles filled with lemonade were hung in the wire of the outside enclosure at a height of $120 \mathrm{~cm}$ and with an interspace of $74 \mathrm{~cm}$. For $30 \mathrm{~min}$ we recorded how long each focal animal spent touching the drinking nipple of either bottle.

During the Food and Enrichment situations we measured from the videos how much each monkey was tolerated by other monkeys that had access to material resources.

(d) Tolerance received (food): During feeding time, we counted the number of times a monkey was allowed to be within arm's length of a monkey receiving a piece of apple.

(e) Tolerance received (enrichment): During provisioning of enrichment, we calculated the total duration a monkey was allowed within arm's length of a monkey possessing one of the two largest pieces of enrichment.

(f) Grooming received: During the focal observations (see above), the total duration of grooming received by the focal animal was recorded.

Note that social behaviour (physical aggression; threat behaviour; neutral/friendly approaches and grooming given) and one resource (grooming received) were measured during observations of each of the two groups outside of the experiments. 


\subsection{Data-analysis}

For each of the six resource measures a path model was fitted to the data. Path analysis, a particular form of structural equation modelling (Schumacker \& Lomax, 2010), is a suitable method to estimate the effects of predictors on a response variable when the direction of the predictive relationships, the assumed causal linkages among predictors and the response variable can be specified at forehand. The estimated path coefficients (standardized linear regression coefficients) indicate the unique effect of each predictor on the response variable, controlled for the direct and indirect effects of the other predictors on the response. In each of the six path models we included the paths from dominance rank to four social behaviours: physical aggression $(N / \mathrm{h})$, threat behaviour $(N / \mathrm{h})$, neutral/friendly approaches $(N / \mathrm{h})$ and grooming given (duration/h). The paths from dominance rank and from each of these four social behaviours to the specific resource were included. These paths were included because we expected the presence of these causal effects (see Introduction). Moreover, two bidirectional paths (between physical aggression and threat behaviour, and between neutral/friendly approaches and grooming given) were included as well, to obtain a sufficient fit of the model. Other bidirectional paths were not included because inclusion did not result in a better fit. All six path models fitted sufficiently well, as indicated by the following five criteria (Hooper et al., 2007): Root Mean Square Error of Approximation (RMSEA) index $=0$, Tucker-Lewis Non-Normed Fit Index $(\mathrm{NNFI})=1$, Bentler Comparative Fit Index $(\mathrm{CFI})=1$ and Standardized Root Mean Square Residual (SRMR) $<0.062$, while the model Chi-square was not significant $\left(X^{2}=2.48, \mathrm{df}=3, p=0.48\right.$ ) for each of the fitted models.

In each of the six path models, the effect of aggression (physical aggression and threat behaviour) and socio-positive behaviour (neutral/friendly approaches and grooming given) on the access to each of the resources is corrected for the direct and indirect effects of dominance rank through these social behaviours on the resource access. Moreover, these effects of the social behaviours (aggression and affiliative behaviour) on accessing resources are also corrected for each other's indirect effects on resource access. Statistical significance of these effects was determined in the following way. All variables of both groups were standardized per group, to control for differences in mean and variance of the variables for the two groups. Since not all variables were normally distributed, a permutation method was applied to obtain $P$ values of the estimated beta's (the path coefficients), based on 
10000 random permutations, where the individual values of each variable are being permutated within each group separately. In addition to these path analyses, we tested the linear correlation between dominance rank and each of the six resource measures using similar permutation tests. All tests were two-sided, with the critical $p$-level set at 0.05 . Analyses were performed in $\mathrm{R}$ version 3.2.3 using the package sem (Fox et al., 2013) to compute the coefficients of the path models and a custom-written $\mathrm{R}$ script to execute the permutation procedure for computing $p$ values of the coefficients.

\subsection{Ethical approval}

All applicable international, national, and/or institutional guidelines for the care and use of animals were followed. All procedures performed in studies involving animals were in accordance with the ethical standards of the institution or practice at which the studies were conducted.

\section{Results}

\subsection{Effect of social behaviour on resource access}

When controlling for the direct and indirect effects of dominance rank on resource access, as well as for the indirect effects of the social behaviours on resource access, using path analysis, we found significant direct effects of social behaviours on access to resources (Figure 1). Individuals with higher rates of physical aggression, while controlling for the other effects, received more food in the experiment $(\beta=0.49, p=0.037$, Figure 1a) and longer lasting access to enrichment $(\beta=0.75, p=0.002$, Figure $1 b)$. In contrast, individuals which threatened more often had less access to enrichment ( $\beta=-0.76, p=0.002$, Figure $1 \mathrm{~b}$ ) and spent less time co-drinking ( $\beta=-0.63, p=0.01$, Figure 1c) and were tolerated less often near enrichment $(\beta=-0.75, p=0.003$, Figure 1e). Individuals which generally showed higher rates of neutral/friendly approaches were able to spend more time co-drinking ( $\beta=0.76, p=0.001$, Figure $1 \mathrm{c}$ ), tended to have longer access to enrichment $(\beta=0.46, p=0.051$, Figure $1 b)$; they were tolerated more often nearby monkeys which were handling enrichment $(\beta=0.81$, $p=0.0007$, Figure 1e), and were groomed less by their group members $(\beta=-0.78, p=0.0006$, Figure 1f). None of the other behaviours had a significant direct effect on resource access (Figure 1). 
The amount of variance in resource access that could be explained by each model varied between the six different resources examined for food $\left(R^{2}=\right.$ $0.50)$, enrichment $\left(R^{2}=0.75\right)$, co-drinking $\left(R^{2}=0.83\right)$, tolerance received during feeding $\left(R^{2}=0.08\right)$, tolerance received during handling enrichment $\left(R^{2}=0.80\right)$ and grooming received $\left(R^{2}=0.40\right)$. The low explanatory value of the model on tolerance received during feeding shows that access to this resource is not explained by the variables in the model (Figure 1d).

\subsection{Effect of dominance rank on resource control}

With regard to the effect of dominance rank of the females on the rates of the social behaviours and on access to the six resources the following results were found (see Figure 1). Dominance rank was significantly correlated with physical aggression $(\beta=0.66, p<0.001)$, threat behaviour $(\beta=0.61$, $p=0.001)$ and neutral/friendly approaches $(\beta=0.74, p<0.001)$, but there was no significant correlation between dominance rank and grooming given ( $\beta=-0.25, p=0.24)$. Rather surprisingly, when controlling for the effects of the social behaviours on resource access, dominance rank had no significant direct effect on resource access for any of the six resources $(-0.14<\beta<0.29 ; p>0.23)$ (see the direct arrows from rank to each of the six resources in Figure 1). In contrast, the simple, non-partial linear correlations between dominance rank and each of the six resources were significant for four out of six resources ( $p$-values obtained via permutation tests): namely for food $(r=0.62, p=0.001)$; enrichment $(r=0.59$, $p=0.003)$; co-feeding $(r=0.58, p=0.002)$; and tolerance received during feeding $(r=0.05, p=0.83)$; while the correlations were not significant for tolerance received during handling enrichment $(r=0.48, p=0.014)$; and grooming received $(r=-0.18, p=0.42)$.

\section{Discussion}

We investigated whether aggressive and affiliative behaviour in female longtailed macaques facilitated access to three material and to three social resources. In five of the six path models variance in resource access could be assigned to predictors included in the model. We found that resource access was achieved through aggressive and affiliative behaviour and not merely by having a high position in the dominance rank. Rather, it seems likely that the high dominance rank of an animal promotes its potential to deploy physical aggression and threat behaviour as well as neutral/friendly approaches 

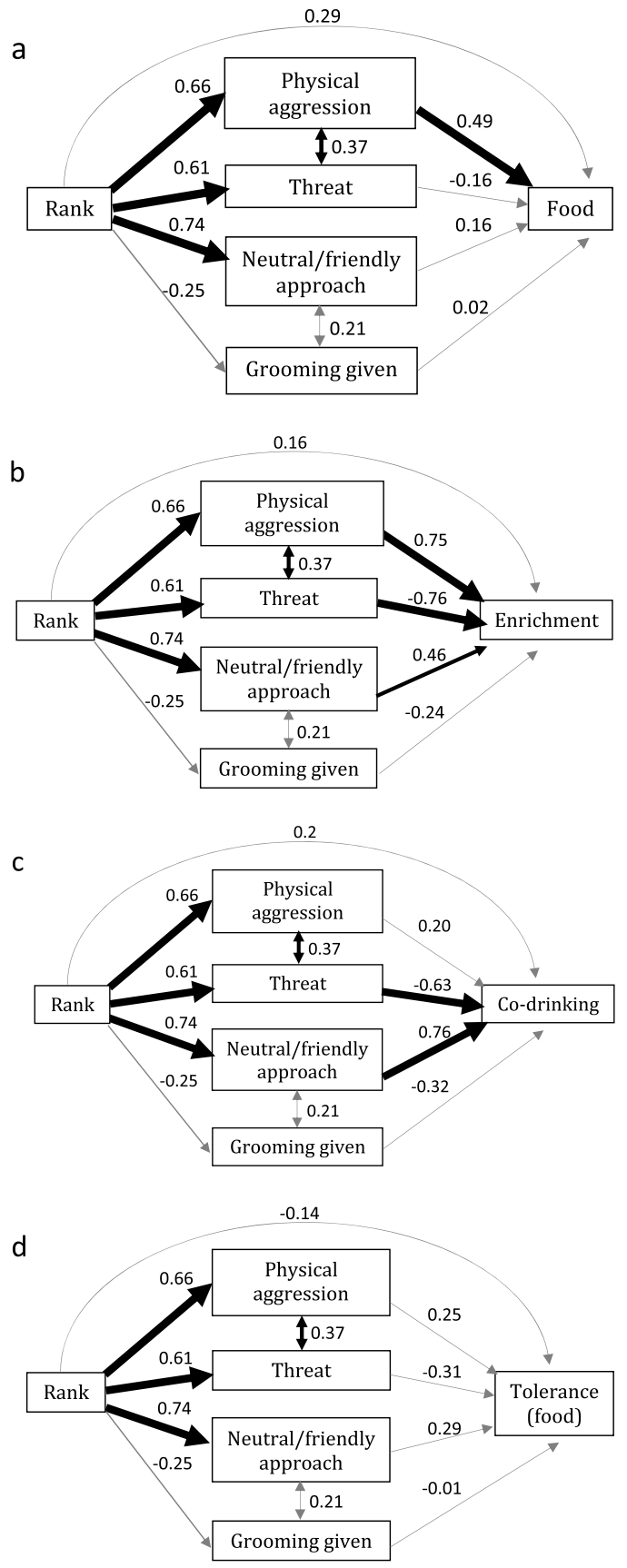

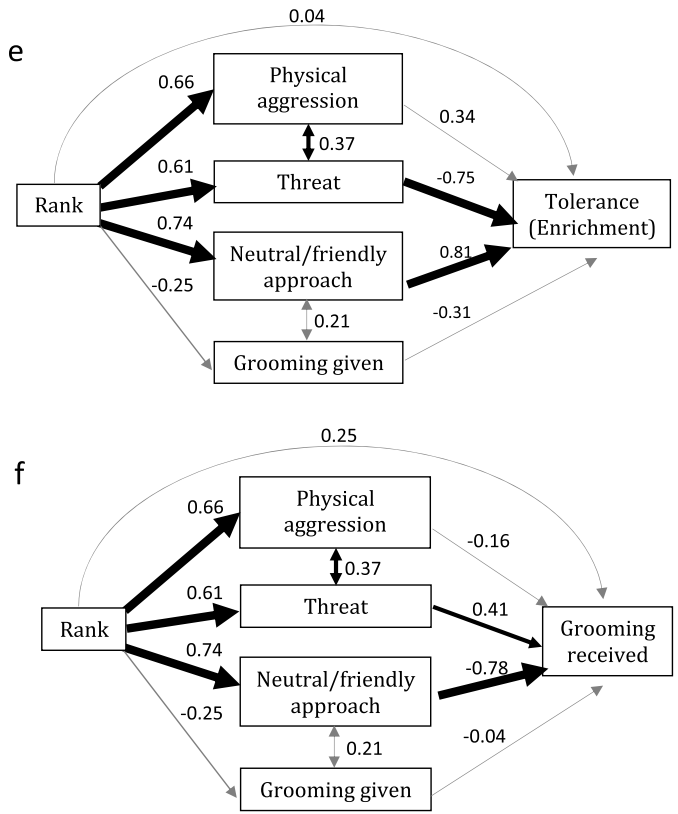

Figure 1. Path model diagrams: values above or to the right of the arrows indicate $\beta$ values corrected for the indirect paths. The width of the arrows corresponds to the significance of the effect: the boldest black arrows indicate significant effects, an intermediate sized black arrow indicates a trend, thin grey arrows indicate insignificant effects. Diagrams (a)-(c): effects on material resources; diagrams (d)-(f): effects on social resources. Note that low rank scores refer to low dominance rank: positive correlations between rank and a behaviour indicate that high-ranking individuals perform this behaviour more often than low-ranking individuals.

of others. Individuals with high rates of aggressive behaviour had better access to material resources, but not to social resources. Individuals with high rates of neutral/friendly approaches had better access to one material resource (co-drinking) and one social resource (tolerance during handling of enrichment). This suggests that the behaviour that may be expected from an individual, based on typically shown rates of behaviour, can predict resource access. Therefore, like results found for children (Charlesworth, 1996; Hawley, 1999; Pellegrini, 2008), both aggression and affiliative behaviour facilitate resource access, but each gives access to different types of resources.

In our study, dominance rank did not have a direct effect on resource access, but an indirect effect via its correlation with aggression and neutral/friendly approaches. Increased expression of overt aggression in highranking individuals is reported in many species, including humans (Benen- 
son, 2013), and was also found in the present study. In contrast, dominant individuals have generally lower levels of affiliative behaviour (humans: Guinote et al., 2015; non-human primates: Seyfarth \& Cheney, 2003; Sapolsky, 2005). In this study however, we found that high-ranking individuals showed high levels of neutral/friendly approaches. Thus, a high dominance rank allows a female long-tailed macaque to deploy multiple social behaviours for accessing different resources. This simultaneous effect of both strategies implies a possible benefit for so-called bistrategic individuals (cf., human children: Hawley, 2003; Roseth et al., 2011). Future studies with a person-centred instead of variable-centred analysis may reveal the relative success of predominantly aggressive, predominantly socio-positive (affiliative) and bistrategic individuals.

Aggressive behaviour was not equally effective for all material resources: while it led to better access to food and enrichment, it did not predict more access to co-drinking. This observation may be related to the dispersal of resources, since the influence of aggressive behaviour on resource access will decrease when resources are more dispersed (Isbell, 1991; Sterck \& Steenbeek, 1997; Pellegrini et al., 2007; Pellegrini, 2008). In our setting, the material resources differed in their spatial distribution. Food was handed out at one location, while for co-drinking always two items were available. Indeed, the effect of physical aggression was stronger for the spatially concentrated food than for the more dispersed co-drinking (Figure 1a and 1c). Likewise, affiliative behaviour may be most effective when resources are more dispersed, since individuals may be able to seek partners that tolerate them. Indeed, affiliative/neutral approaches resulted in co-drinking, but not in more access to food. Regarding the enrichment, the phone book started as one item and after being torn to pieces became very dispersed. Therefore, this resource had a varied distribution. Here, both physical aggression increased and neutral/friendly approaches tended to increase access. This finding suggests that for resources with a varied distribution both aggressive and affiliative behaviours may result in better access. The opposed distributiondependent effects of aggression and affiliative behaviour are interesting and intuitively make sense. In our study, the variation in dispersion within the material resource category was limited and its relationship with the use of social strategies requires further scrutiny.

We expected that physical aggression and threat behaviour would have an equally strong effect on resource access. This expectation was based on 
the premise that threat behaviour signals an individual's attack tendency. Accordingly, we indeed found that high-ranking individuals show both more physical aggression and threat behaviour than low-ranking individuals. The two behaviours are also strongly correlated $(r=0.77)$. Yet, path modelling showed that physical aggression increased access to the material resources food and enrichment, whereas threat behaviour did not enhance resource access (Figure 1a) and had an opposite effect on both access to enrichment and co-drinking (Figure 1b). This counterintuitive result indicates that the use of threat, when controlled for the direct and indirect effects of the other predictors on the response, is not effective and actually seems a signal that reduces access to resources. This remains to be explored further.

In contrast to material resources, high-ranking individuals do not have more access to social resources than low-ranking individuals. Nor was there an indirect effect of dominance rank through aggression on social resources. The only effect of dominance rank on social resources was its indirect effect: individuals with a higher dominance rank more often showed affiliative/neutral approaches; and individuals showing more affiliative/neutral approaches received more tolerance during handling enrichment. Tolerance near a resource may be beneficial, since the tolerated individual may gain access to the resource (Ventura et al., 2006; Carne et al., 2011; Snyder-Mackler et al., 2016; Balasubramaniam \& Berman, 2017). This indicates that receiving tolerance is crucial for access to social resources. In addition, the outcomes on grooming received contrast with the literature on dominant individuals receiving more grooming (for a review, see Schino, 2001). Here the level of analysis becomes important. Our analyses focused on the individual differences in characteristic patterns of behaviour and indicate how an individual typically behaves, similar to the individual-centred approach in personality research (John \& Gosling, 2000; Koski, 2011). Alternatively, access to some social resources may not depend on how an individual typically behaves but may rather concern dyadic measures, that is, how it typically treats particular individuals, such as higher-ranking individuals (Seyfarth, 1977; for a review, see Schino, 2001). These dyadic interactions may concern attraction to kin (Schino, 2001), or affiliative behaviour such as grooming may be exchanged for support (Schino, 2007) or for itself (Barrett et al., 1999, 2000). Indeed, preferential grooming of more dominant individuals is often found in primate female grooming networks (meta-analysis: Schino, 2001; several macaques species: Ventura et al., 2006; Gumert \& Ho, 2008; Carne et al., 2011; Xia et 
al., 2012; Snyder-Mackler et al., 2016). Yet our analysis indicates that this grooming up the hierarchy within a dyad does not translate into dominant individuals receiving overall higher rates of grooming. This outcome can be reconciled with the proposed grooming patterns (Seyfarth, 1977), since it is expected that preferred grooming partners are close in dominance rank. As a result, the preferred grooming partner will differ between individuals and grooming is directed to many individuals in the group. Summarizing, affiliative behaviour and not aggression facilitates access to social resources. Yet, not all social resources may be accessed by overall socio-positive behaviour and may depend on dyadic exchanges. The relative contribution to resource access of the individual rate and dyadic distribution of social behaviour should be further explored.

The amount of tolerance received during feeding could not be explained by any of the factors included in our model. The best predictor for access to food was physical aggression and aggression levels are typically higher during feeding times (Theil et al., 2017). Possibly, the elevated occurrence of aggression during feeding regimes hampered the monkeys to sit with their preferred neighbours. This indicates that in certain situations aggression may impede affiliative behaviour.

This study is to our knowledge the first to investigate the relative importance of aggressive and affiliative behaviour on access to different types of resources in a primate group. We can conclude that dominance rank exerts its influence on resource access indirectly via both aggressive and sociopositive behaviours. Hence, not dominance rank as such facilitates resource access, but dominance rank allows animals to use aggressive and sociopositive behaviour, which in turn facilitates resource access. Moreover, the relative effectiveness of both types of social behaviour depends on the type of resource. This implies that possessing the social skills for employing both types of behaviours comprises the best strategy for resource access. Although it became clear that social resources are less effectively accessed through aggressive behaviour and more effectively through socio-positive behaviour, there may still be other factors determining access to social resources.

\section{Acknowledgements}

The research was funded by seed money from the Utrecht University Strategic Theme Youth \& Identity SM.YI.2013.11.GS to A.H.A. Reijntjes, E.H.M. 
Sterck, M.M. Vermande and H. de Vries. We thank the BPRC animal caretakers for their dedication to the animals and their help in providing food sources and enrichment.

\section{References}

Alberts, S.C. (2012). Magnitude and sources of variation in male reproductive performance. - In: The evolution of primate societies (Mitani, J.C., Call, J., Kappeler, P.M., Palombit, R.M. \& Silk, J.B., eds). The University of Chicago Press, Chicago, IL, p. 412431.

Altmann, J. (1974). Observational study of behavior: sampling methods. - Behaviour 49: 227-267.

Amici, F., Call, J. \& Aureli, F. (2012). Aversion to violation of expectations of food distribution: the role of social tolerance and relative dominance in seven primate species. Behaviour 149: 345-368.

Angst, W. (1974). Das ausdrucksverhalten des javaneraffen Macaca fascicularis Raffles 1821. - Parey, Berlin.

Aureli, F., Cords, M. \& van Schaik, C.P. (2002). Conflict resolution following aggression in gregarious animals: a predictive framework. - Anim. Behav. 64: 325-343.

Balasubramaniam, K.N. \& Berman, C.M. (2017). Grooming interchange for resource tolerance: biological markets principles within a group of free-ranging rhesus macaques. Behaviour 154: 1145-1176.

Banks, E.M., Wood-Gush, D.G.M., Hughes, B.O. \& Mankovich, N.J. (1979). Social rank and priority of access to resources in domestic fowl. — Behav. Process. 4: 197-209.

Barrett, L., Henzi, S.P., Weingrill, T., Lycett, J.E. \& Hill, R.A. (1999). Market forces predict grooming reciprocity in female baboons. - Proc. R. Soc. Lond. B 266: 665-670.

Barrett, L., Henzi, S.P., Weingrill, T., Lycett, J.E. \& Hill, R.A. (2000). Female baboons give as good as they get, but do not raise the stakes. - Anim. Behav. 59: 763-770.

Benenson, J.F. (2013). The development of human female competition: allies and adversaries. - Phil. Trans. R. Soc. Lond. B Biol. Sci. 368: 1-11.

Boccia, M.L., Laudenslager, M. \& Reite, M. (1988). Food distribution, dominance, and aggressive behaviors in Bonnet macaques. - Am. J. Primatol. 16: 123-130.

Cant, M.A. \& Young, A.J. (2013). Resolving social conflict among females without overt aggression. - Phil. Trans. R. Soc. Lond. B Biol. Sci. 368: 1-13.

Carne, C., Wiper, S. \& Semple, S. (2011). Reciprocation and interchange of grooming, agonistic support, feeding tolerance, and aggression in semi-free-ranging Barbary macaques. - Am. J. Primatol. 73: 1127-1133.

Charlesworth, W.R. (1996). Co-operation and competition: contributions to an evolutionary and developmental model. — Int. J. Behav. Dev. 19: 25-38.

Cronin, K.A. (2012). Prosocial behaviour in animals: the influence of social relationships, communication and rewards. - Anim. Behav. 84: 1085-1093.

de Vries, H. (1995). An improved test of linearity in dominance hierarchies containing unknown or tied relationships. - Anim. Behav. 50: 1375-1389. 
de Vries, H. (1998). Finding a dominance order most consistent with a linear hierarchy: a new procedure and review. - Anim. Behav. 55: 827-843.

de Vries, H., Netto, W.J. \& Hanegraaf, P.L.H. (1993). Matman - a program for the analysis of sociometric matrices and behavioral transition matrices. - Behaviour 125: 157-175.

de Waal, F.B.M. (1986). Class structure in a rhesus monkey group: the interplay between dominance and tolerance. - Anim. Behav. 34: 1033-1040.

Drews, C. (1993). The concept and definition of dominance in animal behavior. - Behaviour 125: 283-313.

Fox, J., Nie, Z. \& Byrnes, J. (2013). sem: structural equation models. — R package (version 3.1-6). R Foundation for Statistical Compuyting, Vienna.

Freidin, E., Carbalo, F. \& Bontosela, M. (2017). Direct reciprocity in animals: the roles of bonding and affective processes. - Int. J. Psychol. 52: 163-170.

Guinote, A., Cotzia, I., Sandhu, S. \& Siwa, P. (2015). Social status modulates prosocial behavior and egalitarianism in preschool children and adults. — Proc. Natl. Acad. Sci. USA 112: 731-736.

Gumert, M.D. \& Ho, M.-H.R. (2008). The trade balance of grooming and its coordination of reciprocation and tolerance in Indonesian long-tailed macaques (Macaca fascicularis). Primates 49: 176-185.

Hawley, P.H. (1999). The ontogenesis of social dominance: a strategy-based evolutionary perspective. - Dev. Rev. 19: 97-132.

Hawley, P.H. (2003). Prosocial and coercive configurations of resource control in early adolescence: a case for the well-adapted Machiavellian. — Merrill-Palmer Q. 49: 279-309.

Henzi, S.P. \& Barrett, L. (2002). Infants as a commodity in a baboon market. - Anim. Behav. 63: 915-921.

Herberholz, J., McCurdy, C. \& Edwards, D.H. (2007). Direct benefits of social dominance in juvenile crayfish. - Biol. Bull. 213: 21-27.

Hooper, D., Coughlan, J. \& Mullen, M. (2007). Structural equation modelling: guidelines for determining model fit. — Electr. J. Business Res. Methods 6: 53-60.

Huntingford, F.A. \& Turner, A.K. (1987). Animal conflict. - Chapman and Hall, London.

Isbell, L.A. (1991). Contest and scramble competition: patterns of female aggression and ranging behavior among primates. - Behav. Ecol. 2: 143-155.

Janson, C. (1985). Aggressive competition and individual food-consumption in wild brown capuchin monkeys (Cebus apella). — Behav. Ecol. Sociobiol. 18: 125-138.

John, O.P. \& Gosling, S.D. (2000). Personality traits. — In: Encyclopedia of psychology 6 (Kazdin, A.E., ed.). American Psychological Association, Washington, DC, p. 140-144.

Kaburu, S.S.K. \& Newton-Fisher, N.E. (2015). Trading or coercion? Variation in male mating strategies between two communities of East African chimpanzees. - Behav. Ecol. Sociobiol. 69: 1039-1052.

Kawai, M. (1958a). On the rank system in a natural group of Japanese monkey (I). Primates 1: 111-130.

Kawai, M. (1958b). On the rank system in a natural group of Japanese monkey (II). Primates 1: 131-146. 
Kempes, M.M., den Heijer, E., Korteweg, L., Louwerse, A.L. \& Sterck, E.H.M. (2009). Socially deprived rhesus monkeys fail to reconcile: do they not attempt or not accept reconciliation? - Anim. Behav. 78: 271-277.

Koski, S.E. (2011). Social personality traits in chimpanzees: temporal stability and structure of behaviourally assessed personality traits in three captive populations. - Behav. Ecol. Sociobiol. 65: 2161-2174.

Kulahci, I., Ghazanfar, A.A. \& Rubenstein, D.I. (2018). Knowledgeable lemurs become more central in social networks. - Curr. Biol. 28: 1306-1310.

Kummer, H. (1978). On the value of social relationships to nonhuman primates: a heuristic scheme. - Soc. Sci. Inform. 17: 687-705.

Massen, J.J.M., Sterck, E.H.M. \& de Vos, H. (2010). Close social associations in animals and humans: functions and mechanisms of friendship. — Behaviour 147: 1379-1412.

Mitani, J.C. (1985). Mating behaviour of male orangutans in the Kutai Game Reserve, Indonesia. - Anim. Behav. 33: 392-402.

Muller, M.N., Thompson, M.E., Kahlenberg, S.M. \& Wrangham, R.W. (2011). Sexual coercion by male chimpanzees shows that female choice may be more apparent than real. Behav. Ecol. Sociobiol. 65: 921-933.

Olthof, T., Goossens, F.A., Vermande, M.M., Aleva, E.A. \& van der Meulen, M. (2011). Bullying as strategic behavior: relations with desired and acquired dominance in the peer group. - J. Sch. Psychol. 49: 339-359.

Palombit, R.A., Seyfarth, R.M. \& Cheney, D.L. (1997). The adaptive value of friendship to female baboons: experimental and observational evidence. - Anim. Behav 54: 599-614.

Pellegrini, A.D. (2008). The roles of aggressive and affiliative behaviors in resource control: a behavioral ecological perspective. - Dev. Rev. 28: 461-487.

Pellegrini, A.D., Roseth, C.J., Mliner, S., Bohn, C.M., Van Ryzin, M., Vance, N., Cheatham, C.L. \& Tarullo, A. (2007). Social dominance in preschool classrooms. - J. Comp. Psychol. 121: 54-64.

Pusey, A.E. (2012). Magnitude and sources of variation in female reproductive performance. - In: The evolution of primate societies (Mitani, J.C., Call, J., Kappeler, P.M., Palombit, R.M. \& Silk, J.B., eds). The University of Chicago Press, Chicago, IL, p. 343366.

Pusey, A.E. \& Schroepfer-Walker, K. (2013). Female competition in chimpanzees. — Phil. Trans. Roy. Soc. Lond. B: Biol. Sci. 368: 20130077.

Roseth, C.J., Pellegrini, A.D., Dupuis, D.N., Bohn, C.M., Hickey, M.C., Hilk, C.L. \& Peshkam, A. (2011). Preschoolers' bistrategic resource control, reconciliation, and peer regard. - Soc. Dev. 20: 185-211.

Roulin, A., Des Monstiers, B., Ifrid, E., Da Silva, A., Genzoni, E. \& Dreiss, A.N. (2016). Reciprocal preening and food sharing in colour polymorphic nestling barn owls. - J. Evol. Biol. 29: 380-394.

Sapolsky, R.M. (2005). The influence of social hierarchy on primate health. - Science 308: 648-652.

Schaub, H. (1995). Dominance fades with distance: an experiment on food competition in long-tailed macaques (Macaca fascicularis). — J. Comp. Psychol. 109: 196-202. 
Schino, G. (2001). Grooming, competition and social rank among female primates: a metaanalysis. - Anim. Behav. 62: 265-271.

Schino, G. (2007). Grooming and agonistic support: a meta-analysis of primate reciprocal altruism. - Behav. Ecol. 18: 115-120.

Schino, G. \& Lasio, F. (2018). Competition for grooming partners and interference in affiliation among female mandrills. - Ethology 124: 600-608.

Schino, G., Ventura, R. \& Troisi, A. (2005). Grooming and aggression in captive Japanese macaques. - Primates 46: 207-209.

Schumacker, R.E. \& Lomax, R.G. (2010). A beginner's guide to structural equation modeling. - Routledge, New York, NY.

Seyfarth, R.M. (1977). A model of social grooming among adult female monkeys. J. Theor. Biol. 65: 671-698.

Seyfarth, R.M. \& Cheney, D.L. (2003). Signalers and receivers in animal communication. Annu. Rev. Psychol. 54: 145-173.

Seyfarth, R.M. \& Cheney, D.L. (2012). The evolutionary origins of friendship. - Annu. Rev. Psychol. 63: 153-177.

Silk, J.B. (2002). Using the 'F'-word in primatology. — Behaviour 139: 421-446.

Snyder-Mackler, N., Kohn, J.N., Barreiro, L.B., Johnson, Z.P., Wilson, M.E. \& Tung, J. (2016). Social status drives social relationships in groups of unrelated female rhesus macaques. - Anim. Behav. 111: 307-317.

Soltis, J., Mitsunaga, F., Shimizu, K., Yanagihara, Y. \& Nozaki, M. (1997). Sexual selection in Japanese macaques I: female mate choice or male sexual coercion? - Anim. Behav. 54: 725-736.

Sterck, E.H.M. \& Steenbeek, R. (1997). Female dominance relationships and food competition in the sympatric Thomas langur and long-tailed macaque. - Behaviour 134: 749-774.

Theil, J.H., Beisner, B.A., Hill, A.E. \& McCowan, B. (2017). Effects of human management events on conspecific aggression in captive rhesus macaques (Macaca mulatta). - J. Am. Ass. Lab Anim. Sci. 56: 122-130.

Thierry, B. (2007). Unity in diversity: lessons from macaque societies. - Evol. Anthropol. 16: 224-238.

Tiddi, B., Aureli, F., di Sorrentino, E.P., Janson, C.H. \& Schino, G. (2011). Grooming for tolerance? Two mechanisms of exchange in wild tufted capuchin monkeys. - Behav. Ecol. 22: 663-669.

van Noordwijk, M.A. \& van Schaik, C.P. (1987). Competition among female long-tailed macaques, Macaca fascicularis. - Anim. Behav. 35: 577-589.

van Schaik, C.P. \& van Noordwijk, M.A. (1988). Scramble and contest in feeding competition among female long-tailed macaques (Macaca fascicularis). — Behaviour 105: 77-98.

van Staaden, M.J., Searcy, W.A. \& Hanlon, R.T. (2011). Signaling aggression. — In: Aggression (Huber, R., Bannasch, D.L., Brennan, P. \& Frishman, K., eds). Elsevier/Academic Press, San Diego, CA, p. 23-49.

Ventura, R., Majolo, B., Koyama, N., Hardie, S. \& Schino, G. (2006). Reciprocation and interchange in wild Japanese macaques: grooming, cofeeding, and agonistic support. Am. J. Primatol. 68: 1138-1149. 
Vermande, M.M., Gilholm, P.A., Reijntjes, A.H.A., Hessen, D.J., Sterck, E.H.M. \& Overduin-de Vries, A.M. (2018). Is inspiring group members an effective predictor of social dominance in early adolescence? Direct and moderated effects of behavioral strategies, social skills, and gender on resource control and popularity. - J. Youth Adolescence 47: 1813-1829.

Vernes, M.K. \& Louwerse, A.L. (2010). BPRC's enrichment manual for macaques and marmosets. - Biomedical Primate Research Centre, Rijswijk.

Wilson, E.O. (1975). Sociobiology: the new synthesis. - Harvard University Press, Cambridge, MA.

Xia, D., Li, J., Garber, P.A., Sun, L., Zhu, Y. \& Sun, B. (2012). Grooming reciprocity in female Tibetan macaques Macaca thibetana. — Am. J. Primatol. 74: 569-579. 